\title{
Analysis on the Agglomeration and Radiation Effects of Campus Football Project
}

\author{
Shumin Zhang ${ }^{1}$, Wei Guo ${ }^{1}$ \\ ${ }^{1}$ Jiangxi University of Science and Technology, Nanchang, Jiangxi, 330100
}

Keywords: Campus football project; agglomeration effect; radiation effect

\begin{abstract}
At present, a major problem facing Chinese football is that the overall level of youth football is low and the supply of athletes is insufficient. In response to this situation, the "Twelfth Five-Year Plan for the Development of Sports Industry" also made an in-depth analysis of this. It was found that the reason why the football team of the national team was inconsistent and the development of football was always faltering was mainly the lack of young players. To this end, the State Sports General Administration and the Ministry of Education jointly established a youth campus football project. This paper analyzes the agglomeration and radiation effects of campus football projects from three aspects of resources, geography and policy, in order to provide some reference basis for better promoting the development of campus football project.
\end{abstract}

\section{Introduction}

In recent years, with the continuous development of the national economy, people's living standards have also been significantly improved, and the enthusiasm for the pursuit of various entertainment projects is also growing, especially football sports. Football has always been one of the more popular sports in the world, and the Chinese people are no exception. However, there is still a big gap between the level of Chinese football and the world's advanced level. The reason is mainly due to the lack of young football reserve talents. In order to solve this problem, China has paid more and more attention to the construction of youth campus football projects, aiming at achieving the goal of strengthening the country by improving the level of youth football.

\section{The agglomeration and radiation effects of campus football projects}

In 2009, the state issued the "National Youth Campus Football Activity Implementation Plan". In this program, the number of cities in the autonomous regions, municipalities and provinces that implement campus football activities is clearly defined. At the same time, it is clearly stated which should be The city is determined to be a layout city. Some areas with relevant conditions and certain football traditions use their existing youth football sports foundation to gather together to implement campus football activities. The agglomeration effect can play a leading role in a large area, even in the whole country, and can even be used as a "pilot" project, which can achieve the effect of point-to-face and step-by-step advancement, and can fully demonstrate the effect of radiation effect [1].

Zhidan County in Shaanxi Province, Jiangyan County in Jiangsu Province, and Linying County in Henan Province have achieved relatively satisfactory results in the development of campus football projects. Moreover, in 2011, the country designated these three counties as national campus football pilot counties. The county-level region fully reflects the agglomeration effect of campus football projects. Through the football in the towns and villages of the three counties, the achievements made by them have greatly improved the confidence of implementing the campus football project in other regions, which not only provides important reference value for the development of campus football projects in other regions, but also plays an important role. Leading role.

In addition, Kashgar, Urumqi and Yanbian Korean Autonomous Prefectures in Xinjiang have been established as cities, and a wave of ethnic minority youth football campaigns has been 
launched throughout the autonomous region. At this stage, the three "development poles" areas including the construction of the Corps have been established in Xinjiang. Many members of the Super League team are from Xinjiang, and the most famous ones are Ba Li and Maiti River. They are known as "Uighurs Double Star". The proud achievements of minority football players and the agglomeration effect of campus football projects will certainly promote the implementation of football in minority areas and even the whole country.

The "National Youth Campus Football Activity Implementation Plan" clearly states that at least 30 junior high schools and 60 primary schools should be set as football education schools in the municipality directly under the central government, while at least 16 junior high schools and 30 primary schools in the other cities. According to the survey, there are 2,293 football distribution schools in China, and there are more than 100,000 primary and middle school students participating in football. [2]

However, there are some shortcomings in the agglomeration effect of the campus football project. First, the football distribution schools are mostly non-soccer traditional colleges with good conditions, or traditional football schools, and rarely set up football projects in other types of colleges; Only a small number of schools are located in the suburbs, most of which are concentrated in urban areas, and regional agglomeration is extremely uncoordinated.

\section{Policy agglomeration effect}

In order to ensure the orderly implementation of the campus football project, the relevant departments have promulgated a number of systems and policies. At the same time, they have also clearly defined the quantitative indicators that need to be met during the campus football, and actively promote the development of campus football. In addition, the educational institutions and the layout cities have also compiled some systems that are consistent with their actual conditions in accordance with the policies promulgated by the Ministry of Education and the General Administration of Sport.

The "National Youth Campus Football Activity Implementation Plan" clearly stipulates that the State Sports General Administration shall provide 40 million financial support for each layout city each year, and each layout city shall provide matching funds in a 1:1 manner [3]. At the same time, the institutions of the two major systems of physical education have provided financial support for the development of campus football activities, and all follow the principle of average distribution, and there is no difference in treatment.

The National Youth Campus Football Work Leading Group and the National Campus Football Work Office were jointly created by the Ministry of Education and the General Administration of Sports. The leading team members and office staff are from these two departments. They are mainly responsible for the macroscopic work of campus football. Guide and organize the coordination of campus football work in all autonomous regions, municipalities and provinces. The School Foot Office is jointly organized by the local education administration and the sports administration. It is mainly responsible for guiding the development of campus football activities in various cities. For the school of distribution, the principal is mainly to guide the campus football work, while the physical education teacher is responsible for organizing the campus football activities.

Campus football distribution schools and layout cities play an important leading role, and also play a good radiation effect. By strengthening communication and interaction with non-distribution institutions and non-layout cities, they continue to radiate their experience advantages and resources. The advantage is to expand the influence of football and make football gradually popularized in China.

At this stage, football has gradually been promoted in ethnic minority areas and rural areas. The central, western and eastern regions have set up campus football pilot counties, which has played an effective "aggregation-radiation" effect.

For those remote rural areas with poor conditions, it is more important to set up institutions and layout cities to lead, gather and radiate. The football tradition is formed by the accumulation of bits and pieces, not born. If we want to realize the promotion and popularization of football in remote 
and poor rural areas, we suggest that we can adopt the development strategy of "urban radiation in rural areas and rural encircling cities” [4].

\section{The impact of agglomeration and radiation effects on campus football engineering}

First, it helps to promote the effective implementation of policies. The agglomeration and radiation effects can prompt the country to effectively implement the football project policy, and achieve the goal of popularizing football in designated areas by scientifically formulating policies in designated areas, such as quantifying standards, standardizing processes, and setting goals. Second, it helps to plan financial resources. The agglomeration and radiation effects make the financial resources concentrated in the designated areas, which can expand the football scale in the designated areas, attract more football clubs and sports equipment suppliers to gather here, and promote the effective planning of financial resources. Finally, it helps to make full use of human resources. By setting up a layout city, you can attract a large number of talents to focus on the city and establish a football economic circle. By centralizing the integration of high-level talents, it is not only convenient for centralized management, but also helps high-level talents to learn from each other in the process of communication and interaction, and constantly improve themselves. In addition, arranging high-level instructors and coaches for the layout of the city will also help to improve the level of local football.

On the one hand, it can accelerate the promotion of campus football from the region to the city. Campus football is a complex and long-term project that needs to be gradually promoted, and the agglomeration and radiation effects can accelerate the promotion of campus football. On the other hand, it can speed up the promotion of campus football from the city to the city and county. Although the "National Youth Campus Football Activity Implementation Plan" clearly defines the number of fixed-point institutions, however, due to limited economic conditions, it is currently impossible to achieve the popularity of football in the national primary and secondary schools, while the financial conditions of institutions in urban areas are relatively high. Well, most of the financial and human resources are collected from the city's designated institutions, allowing the city's designated institutions to play a role in demonstration and leading. In addition, the city government will also give city and county institutions a certain financial support and human support to promote the popularization of campus football from the city to the city.

\section{Conclusion}

In summary, the agglomeration and radiation effects of campus football projects are mainly reflected in the three aspects of geography, policy and resources. It not only helps the effective allocation of resources, but also the popularity of campus football, which is promoted by Chinese football. Development is of great significance. It is suggested that the leading role of campus football designated universities and layout cities should be actively played to expand the concentration and radiation effects of campus football, and strive to improve the level of football in China to win the recognition of the world.

\section{References}

[1] Yan Jian, Hu Yong, Li Yanzhen. SWOT Analysis and Development Strategy of Changsha Primary School Campus Football Project[J]. Contemporary Sports Science, 2017(11): 85-87.

[2] Shang Lipei, Cheng Chuanyin. Research on the Social Function and Radiation Effect of Li Ning Sports Park[J]. Journal of Nanjing Institute of Physical Education, 2016(2):138-142.

[3] Zhou Jinfeng. The Significance of Agglomeration-Radiation Effect in Youth Campus Football Project[J], 2015(34):122-122.

[4] Shi Lixin, Du Guangyou. Analysis of the Win-win Effect of College Football Professional Resources on the Campus Football in Primary and Middle Schools[J]. Journal of Yangtze University, 2015(1): 70-73. 